\title{
Psychosocial Implications of the Coronavirus Pandemic: Early Study and Projections from Port Harcourt Nigeria
}

\author{
Nkporbu A K $\mathbf{K}^{1}$, Stanley $\mathbf{C N}^{2}$, Stanley $\mathbf{P C}^{1 *}$ \\ ${ }^{I}$ Department of Neuropsychiatry, University of Port Harcourt Teaching Hospital, Port Harcourt, Nigeria \\ ${ }^{2}$ Department of Pharmaceutical Microbiology, Faculty of Pharmaceutical Sciences, University of \\ Port Harcourt, Nigeria.
}

*Corresponding Author: Stanley PC, Department of Neuropsychiatry, University of Port Harcourt Teaching Hospital, Port Harcourt, Nigeria

\begin{abstract}
Background: The coronavirus pandemic also known as COVID-19 is both a serious threat to human existence and at the same time causing a lot of emotionally traumatic losses to people and nations globally.

Aim: The aim of this study was to assess the psychosocial implications of the coronavirus pandemic on the general population.

Methodology: The study was done through review of the available health service records in the hospital from December 2019 to mid April, 2020. Approval was obtained from the hospital ethical committee to access the records. This was also followed by active search of available online data from the Nigerian Centre for Disease Control (NCDC) and other countries Centre for Disease Control, the World Health Organization as well as emerging literatures from National media. As it was not possible to do a true systematic review, this was only a narrative review. Data were presented in tables.

Results: The review found a high level of fear and apprehension among both health workers as well as the general population occasioned by the high fatality associated with the disease, lack of basic preventive and protective tools, the volume of information and misinformation circulated and the losses occasioned by the lockdowm and restrictions. These and the isolations and seeming stigma for COVID-19 are ready markers for mental disorders such as anxiety, OCD, PTSD, adjustment disorders, sleep disorders and depression among others.

Conclusion: Extensive outbreak of infection to a pandemic scale such as COVID-19, with the associated huge losses, disruption of businesses and global economic loss has the tendency to cause psychological consequences. It is therefore important to include mental health as part of the preventive measures for COVID-19 in other to avert a possible looming Mental Health Epidemic.
\end{abstract}

Keywords: Psychosocial Implications, Covid-19, Early Study, Projections, Port Harcourt Nigeria.

\section{INTRODUCTION}

In late December, 2019, a new variant of coronavirus outbreak resulting in a viral disease referred to as COVID-19started from Wuhan, Hubei Province of China as an Epidemic. Covid-19 presents with non-specific clinical manifestations-headache, fever,, excessive sweating, mild, moderat or severe acute respiratory symptoms. The respiratory symptoms often look similar to that caused by SARS-CoV (severe acute respiratory syndrome Coronavirus). ${ }^{1-5}$ Coronaviruses are a group of enveloped viruses with non- segmented, single stranded and positive-sense RNA genomes. 6- $^{-}$ ${ }^{10}$ SARS-CoV-2 belongs to the beta subgroup of coronaviruses and has $70 \%$ in the genome to SARS-CoV.-5 Covid-19 virus spreads mainly through respiratory droplets of infected persons during speaking, sneezing or coughing. ${ }^{6}$ This transmission can occur directly by contact with an infected person, indirectly by contact with surfaces contaminated by droplets from COVID-19 patients or other less authentic routes such as faeces. ${ }^{6-7}$

The COVID- 19 has since spread beyond China constituting a huge global emergency and concern. ${ }^{11}$ On $30^{\text {th }}$ January, 2020, the World Health Organization(WHO) declared the outbreak a Public Health Emergency of International Concern(PHEIC). ${ }^{12}$ No sooner than later, on March 11, 2020, the outbreak has spread across about $2 / 3$ of the Nations of the world and this necessitated the World Health Organization declaring it a pandemic. ${ }^{13} \mathrm{As}$ at $19^{\text {th }}$ April, 2020, the world has recorded about 2.4 million cases with nearly 177,000 
deaths. ${ }^{14}$ Nigeria recorded its index COVID-19 case on the $27^{\text {th }}$ of February,2020 and as at 19th April, 2020, the number of confirmed cases was 493 with 17 deaths. ${ }^{15}$ By $22^{\text {st }}$ April, 2020, the number of confirmed cases has risen to 782 with 25 deaths. ${ }^{14}$

The SARS-CoV-2 that attacks principally the respiratory systems including the lungs and the bronchioles down to the alveoli. ${ }^{6,7}$ Approximately $80 \%$ of people experience mild symptoms like fever, cough and shortness of breath and is usually self-limiting. ${ }^{6,7}$ The aged, especially those over the age of 65 and those with underlying medical conditions such as Diabetes Mellitus and cardiovascular diseases, may have a more severe form of the viral outcome especially if it reaches their lower lungs and causes pneumonia. ${ }^{2-4}$

The virus is spread mainly through respiratory droplets, and can survive on surfaces for up to 3 days.

The true mortality rate of COVID-19 largely still unknown, but experts currently estimate between $0.6 \%$ to $3 \%$. Based on data from the China Centre of Disease Control, those over age 65 have the highest mortality rate while those under the age of 50 have death rate of less than $1 \% .^{2-5}$ More recent researches suggested the mortality rate overall is likely near $1.4 \%$. Specifically, the age reported mortality rates are stated as follows; ages $0-9$ is $0 \%, 10-39$ is $0.2 \%, 40-49$ is $0.4 \%, 50-59$ is $1.3 \%, 60-69$ is $3.6 \%$, $70-79$ is $8 \%$ while 80 years and above is $14.8 \% .^{3-5}$

A number of factors can affect mortality including the environment and nature of available interventions and the figures cannot be predictive enough as a lot of the information known about COVID-19 now may likely change with time. For instance, some countries are currently reporting higher mortality rate. In the US and Italy, where the health care systems are overwhelmed with the outbreak, the death rate is higher than the average ,around $8 \%$ and $6 \%$ respectively, ${ }^{12}$ meanwhile,South Korea has dearth rate closer to $0.6 \%$. Death rate varies depending on the demographic characteristics of the population of the country and the measures put up to contain the viral spread.

This obviously has a negative toll including psychological problems on global population. ${ }^{16-}$

${ }^{20}$ There have been lockdowns in many parts of the world in order to contain the spread of the deadly viral disease outbreak, and a general global economic slow down. Many businesses have suddenly crumbled with many losses including millions of people been rendered jobless. Oil production and other oil related activities around the globe have equally slowed down. The oil prices have fallen remarkably, and many countries have had to review and adjust their annual budgets. Public and private institutions closed with gross disruptions of peoples plans, targets and budgets.. All these have left the masses with so much fear, apprehension and uncertainty. ${ }^{18}$

In cases where parents were quarantined with children, the mental health toll became even steeper. ${ }^{14-15}$ In one study during Ebola outbreak, no less than $28 \%$ of quarantined parents had diagnosis of 'trauma-related mental health disorder. ${ }^{21}$ Among quarantined hospital staff, almost $10 \%$ reported high depressive symptoms up to three years after being quarantined during the SARS outbreak. ${ }^{14}$ Another study reporting on the long-term effects of SARS quarantine among healthcare workers found a long-term risk for alcohol abuse, self-medication and longlasting "avoidance" behaviour. ${ }^{15}$ This means that years after being quarantined, some hospital workers still avoid being in close contact with patients by simply not showing up for work. Reasons for stress abound in lockdown: there is risk of infection, fear of becoming sick or of losing loved ones, as well as the prospect of financial hardship. ${ }^{18}$ All these, and many more, are present in this current pandemic.

There is already a sharp increase in absenteeism at work in countries in lockdown. ${ }^{14,15}$ People are afraid to catch COVID-19 on the work floor hence avoid work. We will see a second wave of this in three to six months. Just when we need all able bodies to repair the economy, we can expect a sharp spike in absenteeism and burnout. Taking a queu from many examples, after deployment in previous cases of both man made and natural disaster showed absenteeism in high risk areas, for example military, companies that were close to Ground Zero in 9/11 and medical professionals in regions with outbreaks of Ebola, SARS andMERS. ${ }^{4,5,21}$

In general, we know at-risk groups for longterm mental health issues disease out break of this nature will be the healthcare workers who are on the frontline, young people under 30 and children, the elderly and those in precarious situations, for example, due to mental illness, disability and poverty. ${ }^{16,17,22-25}$ 
Furthermore, movements have been greatly restricted in many countries except for workers on essential duties such as hospital, security, utility services. ${ }^{12-14}$ The others have been asked to stay at home. About one month ago, the World Bank said that the economy of the world has leaped into recession. ${ }^{13}$ This appears to be worse with the daily earners which constitute the majority of the population of many developing countries especially with developing economies. In fact, the slow down in economic activities has made an unprecedented number of people lose their jobs globally. ${ }^{12,14}$ Generally, hunger and sufferings has increased among various population with eminent fear of possible faming because of obvious scaling down of Agro activities and a drastic reduction. This has further worsened by insurgency and activities of herdsmen in Nigeria. The tendency for crimes has equally increased as some people are prone to engaging in any acts that can guarantee them the next meal. The global and national outcry has made many countries and state to release many metric tones of their grain reserve. ${ }^{12,15}$

COVID-19 no doubt has generated a number of psychosocial and emotional stress globally. ${ }^{16-20}$ The anxiety and fear of contracting the disease viz-a-viz the high mortality recorded globally has caused enormous emotional tension. ${ }^{14,18}$ Consequently, a lot of preventive measures to contain the deadly disease have been tried including restrictions, lockdown, closure of National and International business operations and educational institutions. ${ }^{12,14}$ These have unleashed untold stress, sufferings and difficulty on people. Many who by these restrictions have had their sources of livelihood stopped may develop anxiety, sleep problems and depression. Furthermore, closure of markets and shops, threw a lot of people into public scare with unprecedented panic buying. ${ }^{13}$ Also, anxiety provoking is the global scarcity of basic preventive materials and management equipments. ${ }^{14}$ These include PPE, face masks, latex gloves, alcohol-based hand sanitizers, ventilators, testing kits and other personal protective equipments. Lack of these materials has heightened the anxiety of the general population as well as the frontline health workers. $^{14,22,23}$

Furthermore, in a bid to contain the spread of the virus, other measures like suspension handshakes and banning of social and religious gatherings like churches, movies and other event centers, recreational centers, clubs houses and many more. ${ }^{12-14}$ These were aimed at ensuring social distancing as it has been identified for now as the most effective measure to prevent human to human spread. This has resulted into some unnecessary stigmatization and timely social interaction and socialization at relaxation centre's which are natural potent antidotes for anxiety and depression. Losses constitute important depressogenic factors. People have lost their businesses and millions of people have lost their jobs. ${ }^{12-14}$ In addition, several other thousand people have lost their loved ones to COVID-19 infection.

The next vulnerable group of immense concern are the Migrants who are prone to various social, psychological and emotional trauma in such situations, emanating from fear of neglect by the local community and concerns about wellbeing and safety of their families. ${ }^{26}$ Migrants are forced to leave their native places in search of better opportunities and earnings, sometime leaving behind their families. In many instances, the families in native places depend partially or entirely on the money sent by the migrant earning members of the family. ${ }^{26}$

During outbreak of communicable diseases, such a COVID-19, and the eventual restrictions imposed on routine activities as part of social distancing norms to prevent the spread of the diseases, scores of migrant workers tend to move back to their native places. During the prevailing COVID pandemic also, many migrant workers used all possible means to reach their destinations. ${ }^{26}$ Many of them are however stuck at borders, including state, district and at national border areas. These are the most marginalized sections of the society who are dependent on daily wages for their living, and may be prone to a lot of distress need empathy and understanding of the society. ${ }^{14}$

Moreso, in the present circumstances, those who lack adequate coping mechanism may become depressed or have anxiety disorders, adjustment or sleep problems (Ref). ${ }^{27-32}$ However, not much is known about the long-term mental health effects of large-scale disease outbreaks as the mental health component of interventions are often left out by many countries. While there is some research on the psychological impact of severe acute respiratory syndrome (SARS) on patients and health-care workers, ${ }^{27}$ not much is known about the effects on ordinary citizens, especially children and adolescents. It is however imperative to note that, COVID-19 is even much more widespread than SARS and 
Psychosocial Implications of the Coronavirus Pandemic: Early Study and Projections from Port Harcourt Nigeria

other epidemics on a global scale, in the recent past has now assumed a pandenue. ${ }^{12-14}$

AIM

The aim of this study therefore was to determine the psychosocial implications of the COVID-19 pandemic on the general population.

\section{MeTHOdOLOGY}

The study was done through review of the available health service records in the hospital from December 2019 to mid April, 2020. Approval was obtained from the hospital ethical committee to access the records. This was also followed by search of available online data from the Nigerian Centre for Disease Control (NCDC) other Nations 'Centre for Disease Control, the World Health Organization as well as emerging literatures National media. As it was not possible to do a true systematic review, this was only a narrative review. Data were presented in tables.

\section{RESUlTS}

Table1. Age and Sex Distribution of confirmed COVID-19 cases in Nigeria (as at 19th, April, 2020)

\begin{tabular}{|c|c|c|}
\hline Age Group & Frequency & Percentage (\%) \\
\hline $0-9$ yrs & 15 & 3.0 \\
\hline 10-19 years & 44 & 8.9 \\
\hline 20-29 years & 71 & 14.4 \\
\hline 30-39 years & 96 & 19.5 \\
\hline $40-49$ years & 103 & 20.9 \\
\hline 50-59 years & 78 & 15.8 \\
\hline 60-5 years & 53 & 10.8 \\
\hline 70-79 years & 21 & 4.2 \\
\hline Above 89 years & 12 & 2.4 \\
\hline Sex & & $70.3 \%$ \\
\hline Male & 347 & $29.6 \%$ \\
\hline Females & 146 & \\
\hline
\end{tabular}

Table2. Socio-demographic characteristics of recorded deaths from COVID 19 in Nigeria (as at 19th, April, 2020)

\begin{tabular}{|c|c|c|}
\hline Age & Frequency $(\mathbf{n = 1 7})$ & $\mathbf{\%}$ \\
\hline$<25$ & 2 & $11.98 \%$ \\
\hline$>25$ & 15 & $88 \%$ \\
\hline Sex & & $47.1 \%$ \\
\hline Males & 8 & $52.9 \%$ \\
\hline Females & 9 & $100 \%$ \\
\hline Education & 17 & $0 \%$ \\
\hline$>$ Secondary education & 0 & $35.3 \%$ \\
\hline No formal education & & $64.7 \%$ \\
\hline History of Recent Travel outside Nigeria & 6 & \\
\hline No history of recent travel & 11 & \\
\hline History of travel & & \\
\hline
\end{tabular}

Table3. General fact sheet (April 19, 2020)

\begin{tabular}{|c|c|c|c|c|c|c|c|c|}
\hline States & $\begin{array}{c}\text { Total } \\
\text { Confirmed } \\
\text { Cases }\end{array}$ & $\begin{array}{c}\text { New } \\
\text { Confirmed } \\
\text { Cases }\end{array}$ & $\begin{array}{c}\text { Total } \\
\text { Confirmed } \\
\text { Cases }\end{array}$ & $\begin{array}{c}\text { New } \\
\text { Confirmed } \\
\text { Cases }\end{array}$ & $\begin{array}{c}\text { Total } \\
\text { Deaths }\end{array}$ & $\begin{array}{c}\text { New } \\
\text { Deaths }\end{array}$ & $\begin{array}{c}\text { Total } \\
\text { Active } \\
\text { Cases }\end{array}$ & $\begin{array}{c}\text { Days } \\
\text { Since Last } \\
\text { Reported } \\
\text { Cases }\end{array}$ \\
\hline Lagos & 283 & 32 & 90 & 0 & 11 & 4 & 182 & 0 \\
\hline FCT & 69 & 2 & 23 & 0 & 2 & 0 & 44 & 0 \\
\hline Kano & 27 & 6 & 0 & 0 & 1 & 0 & 26 & 0 \\
\hline Osun & 20 & 0 & 17 & 0 & 0 & 0 & 3 & 14 \\
\hline Edo & 15 & 0 & 6 & 1 & 1 & 0 & 8 & 3 \\
\hline Oyo & 15 & 2 & 5 & 0 & 0 & 0 & 10 & 0 \\
\hline Ogun & 10 & 1 & 5 & 0 & 0 & 0 & 5 & 0 \\
\hline Katsina & 9 & 2 & 0 & 0 & 1 & 0 & 8 & 0 \\
\hline Kwara & 9 & 5 & 0 & 0 & 0 & 0 & 8 & 7 \\
\hline Kaduna & 6 & 0 & 4 & 4 & 0 & 0 & 2 & 9 \\
\hline
\end{tabular}


Psychosocial Implications of the Coronavirus Pandemic: Early Study and Projections from Port Harcourt Nigeria

\begin{tabular}{|c|c|c|c|c|c|c|c|c|}
\hline Bauchi & 6 & 0 & 3 & 0 & 0 & 0 & 8 & 3 \\
\hline AkwaIbom & 6 & 0 & 3 & 0 & 0 & 0 & 0 & 0 \\
\hline Delta & 4 & 0 & 0 & 0 & 1 & 0 & 3 & 2 \\
\hline Ondo & 3 & 0 & 0 & 0 & 0 & 0 & 3 & 4 \\
\hline Ekiti & 3 & 1 & 2 & 1 & 0 & 0 & 1 & 11 \\
\hline Rivers & 2 & 0 & 2 & 1 & 0 & 0 & 0 & 2 \\
\hline Niger & 2 & 0 & 0 & & 0 & 0 & 2 & 21 \\
\hline Enugu & 2 & 0 & 2 & 0 & 0 & 0 & 0 & 0 \\
\hline Benue & 1 & 0 & 0 & 0 & 0 & 0 & 1 & 20 \\
\hline Anambra & 1 & 0 & 0 & 0 & 0 & 0 & 1 & 7 \\
\hline Total & $\mathbf{4 9 3}$ & $\mathbf{5 1}$ & $\mathbf{1 5 9}$ & $\mathbf{7}$ & $\mathbf{1 7}$ & $\mathbf{4}$ & $\mathbf{3 1 7}$ & \\
\hline
\end{tabular}

Table4. Basic Hospital statistics (University o Port Harcourt Teaching Hospitl, Port Harcourt (as at 19th,April, 2020)

\begin{tabular}{|l|l|}
\hline & \\
\hline Monthly Income & \%Decrease \\
\hline December & $6 \%$ \\
\hline January & $15 \%$ \\
\hline February & $35 \%$ \\
\hline March & $31 \%$ \\
\hline Increase in annual leave application & No of Staff \\
\hline December & 25 \\
\hline January & 31 \\
\hline February & 60 \\
\hline March & 71 \\
\hline
\end{tabular}

\section{DISCUSSION}

The Covid-19 pandemic has alarming implications for individual as well as the population in terms of collective health, emotional and social functioning. The data shown from Nigeria is consistent with the report released on 18 March of the analyses of severity of COVID-19 cases in the United States from 12 February to 16 March by age group. Although mortality is highest in adults over 65 consistent with data reported from China, Italy and elsewhere $-20 \%$ of US hospitalizations occurred in people aged 20-44 years. ${ }^{12-14}$

Apart from the high mortality seen with the COVID-19, the next global concern is the state of mental health of people during and after the outbreak. ${ }^{16-20,30}$ Indeed, there is an impending fear of mental health epidemic. ${ }^{17,18}$ Widespread outbreaks of infectious disease, such as COVID19 , are associated with psychological distress and symptoms of mental illness. ${ }^{17,30}$ As the impact of the coronavirus on the population continues to increase, it is inducing a considerable degree of fear, worry and concern in the population at large and among certain groups in particular, such as older adults, care providers and people with underlying health conditions. ${ }^{18,22-25}$ The main psychological impact to date is elevated rates of stress and anxiety. ${ }^{19}$ More so, as new measures and impacts are being introduced, especially isolation and its effects on many people's routine life and livelihoods, of anxiety, OCD, phobia and PTSD, acute, loneliness, depression, harmful alcohol and drug use, and self-harm or suicidal behavior are also expected to rise. ${ }^{13}$

During disease outbreaks, any individual may be affected emotionally as is happening during the COVID-19 crisis. Everyone reacts or responds differently to stressful situations. How a person responds to the crisis, disasters, outbreaks is influenced by individual background, the differences compared to others, and the community they live in. It is common for individuals to feel stressed, worried and anxious. Fear and anxiety about COVID-19 can be overwhelming and cause strong emotions in an individual. ${ }^{18,19}$

Common responses of people that may be affected varies from one person to the other during an out break of a pandemic dimension. These include worry of possibility that their family members are infected, Fear of falling ill and dying and losing loved ones, feeling helpless - not able to protect loved ones, stress and anxiety especially due to separation (from loved ones and caregivers) because of being quarantined, fear of being placed under home surveillance because of the disease, avoiding health facilities due to fear of becoming infected while in care, fear of not being able to work during isolation, and of being dismissed from 
work and feelings of helplessness, boredom, loneliness and depression due to being isolated. ${ }^{12-14,18,19}$ During the COVID-19 outbreak, a person can experience anxiety and panic symptoms due tolack information or facts, rumours and fake news being spread and influence by social media. Fear and anxiety about a disease can be overwhelming and cause strong emotions in adults and children. ${ }^{16,17}$ Coping with stress will make the individual, the people they care about, and the whole community stronger. ${ }^{20}$ These feelings can be normal in view of the outbreak, however, how you respond makes a difference.

Spending time indoors can cause a different psychological impact depending on how a person reacts and responds to the situation. On a positive note, some can have a positive psychological impact such as improving social connectedness with family members staying in the same indoor environment. However, for some, negative psychological impact such as increased stress due to not being able to perform outdoor routines and activities, not being able to see friends, worry and anxiety about not being able to be physically present to help loved ones and helplessness, boredom, loneliness, and depression can also set in. One of the components of MHPSS is prevention and treatment of psychiatric disorders such as depression, anxiety and post-traumatic stress disorder (PTSD).

Uncertain prognoses, looming severe shortages of resources for testing and treatment and for protecting responders and health care providers from infection, imposition of unfamiliar public health measures that infringe on personal freedoms, large and growing financial losses, and conflicting messages from authorities are among the major stressors that undoubtedly will contribute to widespread emotional distress and increased risk for psychiatric illness associated with Covid-19. Health care providers have an important role in addressing these emotional outcomes as part of the pandemic response. ${ }^{20}$

Extensive research in disaster mental health has established that emotional distress is ubiquitous in affected populations - a finding certain to be replicated in populations affected by the Covid19 pandemic.

After disasters, most people are resilient and do not succumb to psychopathology. Indeed, some people find new strengths. Nevertheless, in "conventional" natural disasters, technological accidents, and intentional acts of mass destruction, a primary concern is post-traumatic stress disorder (PTSD) arising from exposure to trauma. Medical conditions from natural causes such as life-threatening viral infection do not meet the current criteria for trauma required for a diagnosis of PTSD, but other psychopathology, such as Depressive and Anxiety disorders, may ensue.

Some groups may be more vulnerable than others to the psychosocial effects of pandemics. ${ }^{22-25}$ In particular, people who contract the disease, those at heightened risk for it (including the elderly, people with compromised immune status, and those living or receiving care in congregate settings), and people with preexisting medical, psychiatric, or substance use problems are at increased risk for adverse psychosocial outcomes. Health care providers are also particularly vulnerable to emotional distress in the current pandemic, given their risk of exposure to the virus, concern about infecting and caring for their loved ones, shortages of personal protective equipment (PPE), longer work hours, and involvement in emotionally and ethically fraught resourceallocation decisions. Prevention efforts such as screening for mental health problems, psycho education, and psychosocial support should focus on these and other groups at risk for adverse psychosocial outcomes. ${ }^{20}$

Beyond stresses inherent in the illness itself, mass home-confinement directives, including stay-at-home orders, quarantine, and isolation, are new to the generality of human population, particularly the younger generation who had not experienced any pandemic in the last 40 years and raise concern about how people will react individually and collectively. A recent review of psychological sequelae in samples of quarantined people and of health care providers revealed numerous emotional outcomes, including stress, depression, irritability, insomnia, fear, confusion, anger, frustration, boredom, and stigma associated with quarantine, some of which persisted after the quarantine was lifted. ${ }^{23}$ Specific stressors included greater duration of confinement, having inadequate supplies, difficulty securing medical care and medications, and resulting financial losses.

In the current pandemic, the home confinement of large population for indefinite periods, differences among the stay-at-home orders issued by various jurisdictions, and conflicting 
Psychosocial Implications of the Coronavirus Pandemic: Early Study and Projections from Port Harcourt Nigeria

messages from government and public health authorities will most likely intensify distress among the people. A study conducted in communities affected by severe acute respiratory syndrome (SARS) in the early 2000s revealed that although community members, affected individuals, and health care workers were motivated to comply with quarantine to reduce the risk of infecting others and to protect the community's health, emotional distress tempted some to consider violating their orders. ${ }^{5}$

Losses (either material or human) constitute important depressogenic factors. People have lost their businesses and millions of people have lost their jobs. In addition, several other thousand people have lost their loved ones to COVID-19 pandemic. In the present circumstances, those who lack adequate coping mechanisms may become Depressed or have anxiety disorders, adjustment or sleep problems.

To worsen the problems is the fact that opportunities to monitor psychosocial needs and deliver support during direct patient encounters in clinical practice are greatly curtailed in this crisis by large-scale home confinement. Psychosocial services, which are increasingly delivered in primary care settings, are being offered by means of Telemedicine. In the context of Covid-19, psychosocial assessment and monitoring should include queries about Covid-19-related stressors (such as exposures to infected sources, infected family members, loss of loved ones, and physical distancing), secondary adversities (economic loss, for example), psychosocial effects (such as depression, anxiety, psychosomatic preoccupations, insomnia, increased substance use, and domestic violence), and indicators of vulnerability (such as preexisting physical or psychological conditions). ${ }^{20}$ Some patients will need referral for formal mental health evaluation and care, while others may benefit from supportive interventions designed to promote wellness and enhance coping (such as psychoeducation or Cognitive Behavioral Techniques). In light of the widening economic crisis and numerous uncertainties surrounding this pandemic, suicidal ideation may emerge and necessitate immediate consultation with a Mental Health professional or referral for possible emergency psychiatric hospitalization.

The novel nature of SARS-CoV-2, inadequate testing, limited treatment options, insufficient PPE and other medical supplies, extended workloads, and other emerging concerns are potent sources of stress and have the potential to overwhelm the workers and cause emotional tumoil. $^{10,11,24}$

\section{Projections}

The report from the Imperial College COVID19 Response Team, published on 26 March, highlights the importance of acting early to suppress the outbreak. The analysis says that introducing social distancing, testing and isolation of infected people would cut worldwide deaths to 1.9 million, if carried out when each country's fatality rate was 0.2 deaths per 100,000 people per week. Implementing these measures only when the death rate reaches 1.6 per 100,000 people per week would lead to 10.5 million lives lost globally ${ }^{13}$. According to Nature's analysis of death rates from Our World in Data - counting each day at the centre of a rolling weekly window of deaths - Italy hit the 0.2 threshold on 2-3 March, the United Kingdom on 17 March and the United States on 22 March. $^{12}$

With the projection of World bank and the IMF of a global recession that may be sustained till even towards the end of 2021, and with the budgetary review of the federal government of Nigeria that led to the shrinking of both educational and health budget by $25 \%$ each, it is important that the economic and financial experts in the nation should rise up and begin to have consultations even with the agro basis experts and professionals from the ministry of agriculture so as to guarantee sustain adequate food availability for the sustenance of these people, prosperity for farmers and to buffer the huge economic loss occasioned by the oil price losses globally. The COVID-19 pandemic could have infected $90 \%$ of the world's population and killed 40.6 million people if no mitigation measures had been put in place to combat it, according to estimates from an influential modeling group at Imperial College London. ${ }^{14}$

It will be most disastrous if such strategies are not put in place because in the next two years, more would have died from faming in Nigeria than the deaths recorded from COVID-19. By these strategies, we would have averted death that will occur from energy protein malnutrition leading to high susceptibility to infection mostly in our children particularly the Under-5. More so, those in the front line in the care for those infected by COVID-19. Most developed OCD from hand washing while others may develop PTSD especially doctors and nurses who heard about the death of colleagues. 
Psychosocial Implications of the Coronavirus Pandemic: Early Study and Projections from Port Harcourt Nigeria

There are also cases of malingering for example in the hospital within the frontline group. Most people avoid work with frenzy reasons. Others feign illness in other to stay away from work because of fear of contacting the deadly virus in course of caring for infected persons. Malingering $-25 \%$ of health workers hardly come to work. With the fear and the intensity of information and the eventual lockdown due to COVID-19 many tended to have induced phobia. This was evidenced from the records of applications for causal leave which rose from the usual 25 staff per month in January, 2020 to 30 in February, 60 in March, and 71 in April, 2020. Already, both the male and female psychiatry wards of the University of Port Harcourt has had slightly more cases of depression between February and March, 2020.(UPTH Statistics/Record Department).

\section{FUTURE Directions}

AND

\section{RECOMMENDATIONS}

1. Self-care for providers, including Mental Health care providers, involves being informed about the illness and risks, monitoring one's own stress reactions, and seeking appropriate assistance with personal and professional responsibilities and concerns.

2. Health care systems will need to address the stress on individual providers and on general operations by monitoring reactions and performance, altering assignments and schedules, modifying expectations, and creating mechanisms to offer psychosocial support as needed.

3. Nations should dedicate substantial portion of funds to cushion the hardship suffered by their citizens particularly the vulnerable ones.

4. Countries should review their restrictions in line with the evolving epidemiology of the pandemic.

5. As the pandemic continues, it is important to support children and adolescents facing bereavement and issues related to parental unemployment or loss of household income.

6. There is also a need to monitor young people's mental health status over the long term, and to study how prolonged school closures, strict social distancing measures, and the pandemic itself affect the wellbeing of children and adolescents.

7. Reform and engage optimal prudence in the implementation of our National Health Insurance.

\section{CONCLUSION}

When outbreak of the magnitude of COVID-19 occurs, it is usually accompanied by intense fear, apprehension and disruption of functioning which may cause psychological distress. The delivery of MHPSS services to all level of affected persons during COVID-19 will be most appropriate as it follows the principle that basic needs shall be provided to all victims, followed by restoration of community and family support and followed by focused and specialized services to a smaller subgroup within those affected by crisis.

\section{REFERENCES}

[1] Bogoch, A. Watts, A. Thomas-Bachli, C. Huber, M.U.G. Kraemer, K. Khan, Pneumonia of unknown etiologyu in wuhan, China: potential for international spread jvia commercial air travel, J. Trav. Med. (2020),

[2] Lu, C.W. Stratton, Y.W. Tang, Outbreak of pneumonia of unknown etiolokgy in wuhan China the mystery and the miracle, J. Med. Virol. 92 (4) (2020) 401-402.

[3] S. Zhao, Q. Lin, J. Ran, S.S. Musa, G. Yang. W.Wang, et al.., preliminary estimation of the basic reproduction number of novel coronavirus (2019-n CoV) in China, from 2019 to 2020-: a data-driven analysis in the early phase of the outnbreak, Int. J Infect Dis: IJID: off. Publ. Int. Soc. Infect. Dis. 92 (2020) 2q14-217.

[4] Oxford JS, Bossuyt S, Lambkin R. A new infectious disease challenge: Urbani severe acute respiratory syndrome (SARS) associated coronavirus. Immunology. 2003;109:326-328.

[5] Cleri DJ, Ricketti AJ, Vernaleo JR. Severe acute respiratory syndrome (SARS) Infect. Dis. Clin. North Am. 2010;24:175-202. • Reviews the sources of severe acute respiratory syndrome coronavirus (SARS-CoV) in nature.

[6] Adhikari S.P., Meng S., Wu Y.-J., Mao Y.-P., Ye R.-X., Wang Q.-Z., Sun C., Sylvia S., Rozelle S., Raat H., Zhou H. Epidemiology, causes, clinical manifestation and diagnosis, prevention and control of coronavirus disease (COVID-19) during the early outbreak period: a scoping review. Infect. Dis. Poverty. 2020; 17(9):29.

[7] A. Du Toit, outbreak of a novel coronavirus, Nat. Rev. Microbiol. 18 (123) 2020), https://doi:org/10.1038/41579-020-0332-0.

[8] L.L Ren, Y.M. Wang, Z,Q.Wu, Z.C Xiang, L. Guo, T. $\mathrm{Xu}$, et al., identification of a novel coronavirus causing serve pneumonia in $\mathrm{j}$ human a descriptive study, Chinese Med J (2020).

[9] H. Nishiura, S.M. Jung. N.M. Linton, R. Kinoshita, Y. Yang, K. Hayashi, et al, the extent of transmission of novel coronavirus in Wuhan, China, 2020, J. Clin. Med. 9 (2020). 
Psychosocial Implications of the Coronavirus Pandemic: Early Study and Projections from Port Harcourt Nigeria

[10] M. Bassetti, A. Vena, D. Roberto Giacobbe, The Novel Chinese coronavirus (2019-nCoV) Infection: challenges for fighting the storm, Eur. J. Clin. Invest. (2020).

[11] M.I. Holshue, C. DeBolt, S. Lindquist, K.H. Loy, J. Wiesman, H. Bruce, et al., first case 2019 novel coronavirus in the United States, N.Engl. J.Med. (2020).

[12] Rolling updates on Coronavirus disease (COVID-19), $20^{\mathrm{TH}}$ April, 2020; WHO.

[13] ITU-WHO Joint Statement unleashing information technology to defeat COVID-19.

[14] Rapid risk assessment: Coronavirus disease 2019(COVID-19) in the EU/EEA and the UK$9^{\text {th }}$ Update, $23^{\text {rd }}$ April, 2020.

[15] Nigerian Center for Disease Control (NCDC). National Strategy to scale up Access to Coronavirus disease testing in Nigeria, $20^{\text {th }}$ April, 2020. CDC

[16] Ravi Philip Rajkumar. COVID-19 and mental health: A review of the existing literature.Asian Journal of Psychiatry. 2020; published online April 14. https://doi.org/10.1016/S2352-4642 (20) 30109-7

[17] Dong L., Bouey J. Public mental health crisis during COVID-19 pandemic, China.Emerg. Infect. Dis. 2020;23(26) [Epub ahead of print]

[18] Asmundson G.J.G., Taylor S. Coronaphobia: fear and the 2019-nCoV outbreak. J. Anxiety Disord. 2020;70

[19] Asmundson G.J.G., Taylor S. How health anxiety influences responses to viral outbreaks like COVID-19: what all decision-makers, health authorities, and health care professionals need to know. J. Anxiety Disord. 2020; 71: 102211.

[20] Banerjee D. The COVID-19 outbreak: crucial role the psychiatrists can play. Asian J. Psychiatr. 2020;51

[21] Jude MaryCéna et al (2020, A systematic review of mental health programs among populations affected by the Ebola virus disease. Journal of Psychosomatic Research. Volume 131, April 2020, 109966

[22] Chen Q., Liang M., Li Y., Guo J., Fei D., Wang L., He L., Sheng C., Cai Y., Li X., Wang J., Zhang Z. Mental health care for medical staff in China during the COVID-19 outbreak. Lancet Psychiatry. 2020; 7(4):e15-e16.
[23] Kang L., Li Y., Hu S., Chen M., Yang C., Yang B.X., Wang Y., Hu J., Lai J., Ma X., Chen J., Guan L., Wang G., Ma H., Liu Z. The mental health of medical workers in Wuhan, China dealing with the 2019 novel coronavirus. Lancet Psychiatry. 2020;7(3):e14.

[24] Zhu Y., Chen L., Ji H., Xi M., Fang Y., Li Y.The risk and prevention of novel coronavirus pneumonia infections among inpatients in psychiatric hospitals. Neurosci. Bull. 2020; 36 (3):299-302.

[25] Yang Y., Li W., Zhang Q., Zhang L., Cheung T., Xiang Y.-T. Mental health services for older adults in China during the COVID-19 outbreak. Lancet Psychiatry. 2020;7(4):e19.

[26] Liem A., Wang C., Wariyanti Y., Latkin C.A., Hall B.J. The neglected health of international migrant workers in the COVID-19 epidemic.Lancet Psychiatry. 2020;7(4):e20.

[27] Maunder R.G. Was SARS a mental health catastrophe? Gen. Hosp. Psychiatry. 2009; 31 (2009):316-317.

[28] Ho C.S., Chee C.Y., Ho R.C. Mental health strategies to combat the psychological impact of COVID-19 beyond paranoia and panic. Ann. Acad. Med. Singapore. 2020;49(1):1-3.

[29] Lima C.K.T., Carvalho P.M.M., Lima I.A.A.S., Nunes J.V.A.O., Saraiva J.S., de Souza R.I., da Silva C.G.L., Neto M.L.R. The emotional impact of Coronavirus 2019-nCoV (new coronavirus disease) Psychiatry Res. 2020;287

[30] Xiao H., Zhang Y., Kong D., Li S., Yang N. Social capital and sleep quality in individuals who self-isolated for 14 days during the coronavirus disease 2019 (COVID-19) outbreak in January 2020 in China. Med. Sci. Monit. 2020;26

[31] Bao Y., Sun Y., Meng S., Shi J., Lu L. 2019nCoV epidemic: address mental health care to empower society. Lancet. 2020;22(395):e37-e38.

[32] Duan L., Zhu G. Psychological interventions for people affected by the COVID-19 epidemic. Lancet Psychiatry. 2020;7(4):300-303

[33] Shigemura J., Ursano R.J., Morganstein J.C., Kurosawa M., Benedek D.M. Public responses to the novel 2019 coronavirus $(2019-\mathrm{nCoV})$ : mental health consequences and target populations. Psychiatry Clin.Neurosci. 2020; (February)

Citation: Nkporbu A K et al., "Psychosocial Implications of the Coronavirus Pandemic: Early Study and Projections from Port Harcourt Nigeria”, International Journal of Research Studies in Medical and Health Sciences. 2020; 5(4): 31-39.

Copyright: (C) 2020 Nkporbu A K et al., This is an open-access article distributed under the terms of the Creative Commons Attribution License, which permits unrestricted use, distribution, and reproduction in any medium, provided the original author and source are credited. 